debates 


\title{
Conexionistas y facilitadores: los agentes culturales acuñan
}

\author{
Connectionist and Facilitators: Cultural Agents Wedge \\ Conexionistas e facilitadores: agentes culturais acunham
}

\section{Doris Sommer}

HARVARD UNIVERSITY, ESTADOS UNIDOS

Profesora del Departamento de Literatura y Lenguajes Romances, Harvard

University. PhD en Literatura Comparada, Rutgers University. Autora de Bilingual Aesthetics: A New Sentimental Education (Duke University Press, 2004), Proceed with Caution, When Engaged by Minority Writing in the Americas (Harvard University Press, 1999) y Foundational Fictions: The National Romances of Latin America (University of California Press, 1993). Editora de Cultural Agency in the Americas (Duke University Press, 2005) y de Bilingual Games: Some Literary Investigations (Palgrave

Macmillan, 2004). Correo electrónico: dsommer@fas.harvard.edu

\section{Ensayo}

Documento accesible en línea desde la siguiente dirección: http://revistas.javeriana.edu.co

doi:10.11144/Javeriana.CL18-36.cfac

Cómo citar este ensayo:

Sommer, Doris. "Conexionistas y facilitadores: los agentes culturales acuñan". Cuadernos de Literatura 18.36 (2014): 18-24. http://dx.doi.org/10.11144/Javeriana.CL18-36.cfac

\section{(c)}


El aCElerado Ritmo de cambios sociales, económicos, políticos e identitarios en el siglo XXI nos obliga a innovar de muchas maneras, para entender las dinámicas y de allí participar en ellas. Con arte aprovechamos la inestabilidad para co-crear prácticas equitativas que permitan el mayor desarrollo posible de derechos y recursos. Innovar requiere y genera nuevos conceptos y palabras; los neologismos no son puntos de partida, sino efectos posteriores al pensamiento creativo, plasmado en signos que concretizan una intuición en herramienta de construcción. Por eso Kant celebraba el arte como el medio de comunicación de percepciones o ideas tan nuevas e inseguras que todavía carecían de nombres. El arte es el medio que permite explorar lo novedoso que, al inventar o resignificar palabras, facilita la comunicación de los nuevos conceptos. Raymond Williams acuñó a su vez el concepto de "estructura sentimental" para captar el momento pre-conceptual en el que se gesta una nueva idea a través del juego entre la imaginación y la comprensión que permite el arte (Culture and Society).

Esto quiere decir que entre las obras creadas por las experimentaciones artísticas está el vocabulario que describe sus logros. La circularidad es inevitable. Antes de producir un estilo barroco, por ejemplo, la palabra tenía otro significado; lo mismo pasa con el concepto de "montage", o con el de "melodrama". Las palabras se reclutan retrospectivamente, para legitimar algo ya familiar que todavía no tiene nombre.

Esta reflexión innecesariamente postergada sobre los neologismos como derivados de las prácticas innovadoras podría haberme sacado de muchos sinsabores como maestra, de complejas y no siempre exitosas explicaciones de teoría literaria, de tanteos de articulación con campos aledaños (sociología, estética, antropología, economía, política, etc.). Ahora, como muchos maestros que han disfrutado una larga carrera, mi alegre y algo bochornosa conclusión es que las cosas son más sencillas de lo que una imaginaba: los saberes se dejan conocer por los vocablos y usos que han tenido que formular. Las palabras clave que se fraguan para explicar una u otra teoría ya representan dicha teoría de manera sintética; fueron acuñadas o re-significadas para tal propósito. Esto quiere decir que la manera más fácil y segura de entrar en materia teórica no es desenredar una línea de pensamiento, sino identificar su vocabulario peculiar. Las palabras se ajustan a la medida del pensamiento que queda plasmado en ellas. O sea, estudiar el léxico no es exactamente un atajo para captar argumentos poco familiares; es más bien aprovechar su eficiente destilación.

Aquí ofrecemos algunas palabras sueltas, labradas en distintos talleres discursivos, para dar inicio al léxico que vamos generando como agentes culturales. Queda claro que a falta de tal léxico en vías de hacerse no contamos con los 
conceptos ni argumentos que se puedan poner a prueba o difundir. La doble invitación al lector es tanto a desarrollar las incipientes definiciones que ofrecemos a continuación como a aportar los términos que falten, descubrimientos que nos cedan paso - en una metáfora de Wittgenstein - a ciudades extranjeras o en vías de construirse.

Mencionar palabras claves nos remite necesariamente a la obra de Raymond Williams como precursor y guía. Su Keywords (1976) es libro de referencia para muchos, pero Williams lo había empezado a preparar con humildes intenciones, como apéndice o notas al calce de Culture and Society. Al editor le pareció excesivo explicar palabras que todos usaban y no quiso aumentar el número de páginas, por lo que Williams guardó la lista, aumentándola a lo largo de veinte años. Finalmente produjo un léxico mucho más extenso que el original, una serie de respuestas a sus dudas respecto al uso de un lenguaje aparentemente común. El prólogo de Keywords da cuenta de la crisis de comprensión que dio pie tanto al libro de ensayos en 1958 como a la presente destilación léxica. Es que Williams no entendía, dice, los significados de palabras comunes y corrientes - como "cultura", por ejemplo- cuando regresó en 1945 del campo de batalla al campus de Cambridge. En la universidad ya no hablaban el mismo idioma de hacía apenas cuatro años y medio, un síntoma de profundos cambios sociales, políticos, económicos. Williams logra rastrear los cambios a través de su labor de lexicógrafo y generosamente acuña nuevos conceptos, como "estructura del sentimiento", por ejemplo, que ya mencionamos como clave del proceso de generar neologismos.

Pero es la inspiración de Roland Barthes la que quizás sea aun más sugerente para nuestro ejercicio como agentes culturales. Darles nombres a los procesos de agenciamiento a través de las artes, procesos que pasan por debajo del radar académico, nos acerca al defensor del discurso del amor, discurso básico pero demasiado irregular y sorprendente como para considerarse uno de los saberes respetables. En vez de explorar lo que quieren decir palabras que están en boca de todos pero cuyos significados difieren significativamente, como se lo propuso Williams, Barthes rescata palabras que ya nadie, o casi nadie, usa en público. Rescata el vocabulario del amor. Fragmentos de un discurso amoroso (1977) es publicado casi simultáneamente con Palabras clave; ambos libros recurren a un orden alfabético, quiere decir, un desorden arbitrario con el efecto democratizante entre palabras que no obedecen a jerarquías de causa y efecto, ni de estructuras y superestructuras. Importa poco cuál de las muchas entradas se lee primero, así como tampoco importa por qué vía uno entra en el discurso de la cultura y la sociedad, o en el del amor. Los puntos de entrada son circunstanciales, pero 
la fascinación con un vocablo u otro nos detiene los dedos sobre la página para conocer más palabras, y para seguir hojeando.

La necesidad de este libro se sustenta en la consideración siguiente: el discurso amoroso es hoy de una extrema soledad. Es un discurso tal vez hablado por miles de personas (¿quién lo sabe?) pero al que nadie sostiene; está completamente abandonado por los lenguajes circundantes: o ignorado o despreciado, o escarnecido por ellos, separado no solamente del poder sino también de sus mecanismos (ciencias, conocimientos, artes). Cuando un discurso es de tal modo arrastrado por su propia fuerza en la deriva de lo inactual, deportado fuera de toda gregariedad, no le queda más que ser el lugar, por exiguo que sea, de una afirmación. Esta afirmación es, en suma, el tema del libro que comienza. (Barthes 12)

De manera similar, el discurso de las artes en sus funciones cívicas y prácticas ha sido marginado a otra orilla de los saberes reconocidos por respetables instituciones. Esta soledad del quehacer artístico - cotidiano y social- es el empobrecimiento que lleva a John Dewey, en El arte como experiencia (1932), a lamentar el encarcelamiento de "obras" descontextualizadas en los museos y galerías, que le quita a cierta urna o imagen el encanto que tuviera para el usuario como utensilio o estandarte. $\mathrm{El}$ arte es práctico para Dewey, y se reconoce en la experiencia de excitación, de ser conmovido y querer entrar en el juego y seguir produciendo. Dewey celebra los procesos creativos en la vida cotidiana, la capacidad de innovación que tenemos como seres humanos de avanzar en la co-creación del mundo, capacidad que Friedrich Schiller acuñara en 1794 como la pulsión a jugar, la Spieltrieb.

Quizás el silencio en torno a cómo el arte obra en el mundo se debe al hecho de que su ubicuidad queda por sentada, a que sería redundante insistir. Una década antes que escribieran Williams y Barthes sus glosarios respectivos, Pierre Macherey hizo la aguda observación de que lo que más nos revelan los libros es lo que menos dicen. Si en una sociedad se comparten profundamente unos fundamentos, quedan claros sin tener que articularlos. Es precisamente lo que no se dice, paradójicamente los silencios, los que nos informan sobre las creencias y las reglas de una sociedad. Si tuvieran que articularse en discurso, sería señal de que requieren defenderse frente a posibles objeciones o alternativas (Macherey). Esta seguridad que queda sin decir imposibilita el debate, el desarrollo, el desempeño de una idea en obras y en las consecuencias que generan más ideas. Imposibilita el agenciamiento cultural. Descubrir los silencios es un comienzo, no una finalidad. El propósito de Macherey como crítico literario es un primer 
paso para los agentes culturales: participar en el análisis social del que parecían estar excluidas las humanidades por el marxismo científico. El próximo paso es hacer valer el análisis para promover prácticas innovadoras, prácticas que forjan y también se nutren de un léxico en vías de formularse. Macherey llamó la atención a la crítica literaria como campo indebidamente silenciado, despreciado, a pesar de descubrir dinámicas generadoras, ignoradas por otros campos. Su aporte ha sido, quizás, más gratamente acogido por los críticos literarios que por los científicos sociales que siguen aferrados a discursos "científicos", aun cuando saben que la palabra fue acuñada para otros usos y que se toma prestada para los estudios sociales a manera de metáfora (Sommer, Mockus y Hernández).

Es hora de tantear definiciones y usos compartidos que nos permitan colaborar entre humanistas, sociólogos, politólogos, antropólogos, economistas, etc., y otros artistas de medios visuales, escénicos y literarios. Mientras yo voy sugiriendo una lista incipiente de futuras entradas (algunas con los nombres de sus autores), los invito a ustedes, los lectores, a co-formular y proponer muchas más entradas.

Admiración (sentimiento de ciudadanía, Antanas Mockus)

Alegoría (artefacto dialéctico entre la naturaleza y la historia, entre la creación y el hallazgo, Walter Benjamin).

Anfibios (traductor, comunicador, de un registro cultural a otro, Antanas Mockus)

Arte (artificio con intención de detener y dificultar la comprensión, Viktor Shklovsky)

Bello (lo que agrada sin intereses ni conceptos, Immanuel Kant)

Catarsis (purga de la rebeldía, Aristóteles; destierro de la mentalidad policial, Augusto Boal) Color (elemento estructural en el Renacimiento de Tirana, Albania, Edi Rama)

Conexionista (agente que fragua colaboraciones, Pedro Reyes)

Cultura ciudadana (articular ley, moral y cultura, Antanas Mockus)

Cuña (por donde se entra para cambiar sistemas caducos, Paulo Freire)

Decir (el acto de comunicación, distinto del menaje, Said, Emmanuel Levinas)

Distribución de lo Sensible (vía de acceso al arte y a su producción, Jacques Ranciere)

Empatía (tentación de reemplazar al otro o de ser reemplazado, Augusto Boal)

Espect-actor (participante del público, con derecho de intervenir en el escenario, Augusto Boal)

Estética (reflexión intersubjetiva a partir del impacto de lo bello, Immanuel Kant) 
Ética (primera filosofía, Emmanuel Levinas)

Experiencia (sacudimiento generador que opera el arte,John Dewey)

Extrañamiento (efecto de hacer lo familiar raro, sorprendente, Viktor Shklovsky)

Facilitador (multiplicador de una práctica creativa, Augusto Boal)

Guerra de posición (campaña cultural, a diferencia de ataque frontal, Antonio Gramsci)

Foro teatral (improvisación interactiva para explorar opciones más allá de la tragedia, Augusto Boal)

Habitualización (generadora de indiferencia, Viktor Shklovsky)

Hegemonía (acuerdo entre desiguales, Antonio Gramsci)

Infinito (otredad atemporal e incognoscible, Emmanuel Levinas)

Ingenio (efecto de la condensación y/o el desplazamiento semiótico, Sigmund Freud)

Juicio (facultad innata de la sociabilidad desarrollada por medio de la estética, Immanuel Kant)

Lector (posición pagada por torcedores de tabaco en el Caribe hispano, Tampa, NY)

Maestro ignorante (facilitador, en lugar de explicador, Jacques Rancière)

Performance (conciencia de artificio en su actuación, Augusto Boal, Diana Taylor)

Placer (necesario sentimiento compartido para generar cambios positivos, Antanas Mockus)

Pre-Textos (capacitación de maestros para facilitar interpretaciones artísticas de libros clásicos)

Proyección (introyección de imágenes sobre edificios y monumentos públicos, por ejemplo, K. Wodizko)

Reciclar (base de todas las artes, notorio en la red de Cartoneras, editoras con cartón reciclado)

Responsabilidad (mi obligación no recíproca con el otro, Emmanuel Levinas)

Restricciones, fuertes y débiles (condiciones para decisiones racionales, Jon Elster)

Secreto (demanda de información privilegiada para afirmar la autoridad, Rigoberta Menchú)

Sentido común (acuerdo intersubjetivo después del juicio estético, Immanuel Kant)

Silencio (indicador de ideas y valores fundamentales compartidos, Pierre Macherey)

Simpatía (sentimiento que permite la solidaridad, Augusto Boal)

Sorpresa (efecto fundamental del arte, falta de comprensión inmediata y curiosidad)

Spieltrieb (la pulsión a jugar; sana la pugna entre la razón y la sensualidad, Friedrich Schiller) 
Sub-arte (práctica creativa social, sin pretensión al desinterés, Antanas Mockus)

Sublime (efecto estético procesado de un horror o miedo superado por la razón, Immanuel Kant)

Tragedia (la pérdida de la imaginación; asumir que nada puede hacerse, Augusto Boal)

Transaccional (la dinámica recíproca entre el aprendizaje y la enseñanza, John Dewey, Paulo Freire)

\section{Obras citadas}

Barthes, Roland. Fragmentos de un discurso amoroso. México: Siglo XXI, 1982.

Macherey, Pierre. Pour une théorie de la production

littéraire. París: François Maspero, 1966.

Sommer, Doris, Antanas Mockus y Carlos Augusto Hernández. "A la luz del juego: los otros oscurantismos". Ponencia leída en el Congreso

Oscurantismos organizado por Jon Elster y Antanas Mockus. Universidad Nacional de Colombia, Bogotá, 12 de diciembre de 2013.

Williams, Raymond. Culture and Society. Londres: Chatto and Windus, 1958.

-. Palabras clave. Un vocabulario de la cultura y la sociedad. Trad.

Horacio Pons. Buenos Aires: Nueva Visión, 2003. 